\title{
Sample Preparation Methods for the Determination of the Antioxidative Capacity of Apple Juices ${ }^{\dagger}$
}

\author{
Iva Juranović Cindrić, ${ }^{\text {a,* }}$ Martina Kunštić, ${ }^{\text {a }}$ Michaela Zeiner, ${ }^{\text {b }}$ \\ Gerhard Stingeder, ${ }^{b}$ and Gordana Rusak ${ }^{\mathrm{c}}$ \\ ${ }^{a}$ Laboratory of Analytical Chemistry, Department of Chemistry, Faculty of Science, University of Zagreb, \\ Horvatovac 102a, HR-10000 Zagreb, Croatia \\ ${ }^{\mathrm{b}}$ Division of Analytical Chemistry, Department of Chemistry, University of Natural Resources and \\ Life Sciences (BOKU), Muthgasse 18, 1190 Vienna, Austria \\ ${ }^{\mathrm{c}}$ Department of Biology, Faculty of Science, University of Zagreb, Marulićev trg 9a, HR-10000 Zagreb, Croatia
}

\begin{abstract}
The elevated ecological awareness nowadays led to a higher consumption of apples juices. Apples juices are rich in dietary fiber, pectin, potassium, and vitamins A and $\mathrm{C}$ as well as in different classes of phenolic compounds, which can protect the human body against oxidative stress by scavenging oxygen free radicals. During production and storage some bioactive compounds might decompose resulting in a reduced antioxidative capacity.

Common methods for the determination of the antioxidative capacity of other food stuff are based on the extraction of the compounds under study using acetone, which is senseless in aqueous juices. But acetone might have an influence on the compounds responsible for the antioxidative capacity. Thus, self made apple juice samples were analyzed without organic solvent as well as mixed with acetone to see differences caused by the solvent. The results obtained with both procedures were compared using a paired $t$-test in order to see statistically significant differences in the results. No statistically significant differences were found between the testing with and without acetone. Thus the time of analysis, the amount of solvents needed, and the required labor force can be reduced without loosing analytical quality. Total content of phenolic compounds ranged from 400 to $650 \mathrm{mg}$ gallic acid equivalent/L (Folin-Ciocalteu method) and antioxidative capacity from 1.0 to $1.6 \mathrm{mmol}$ Trolox $^{\circledR} / \mathrm{L}$ (ABTS assay). (doi: 10.5562/cca1756)
\end{abstract}

Keywords: apple juice, antioxidative capacity, Folin-Ciocalteu method, ABTS assay

\section{INTRODUCTION}

Fruit juices are nutritious and due to the increased awareness of healthy lifestyle becoming more and more popular drinks. The consumption of apple juice has rapidly increased in the 1990s and is now constant at a high per capita level of approximately 13 liter/year. ${ }^{1}$

Apples are widespread fruits being a rich source of dietary fiber, pectin, potassium, and vitamins $\mathrm{A}$ and $\mathrm{C}$. Overall, in vitro but also in vivo studies begin to define mechanisms by which bioactive substances from apples may help prevent chronic diseases. Besides $75-95 \%$ of water, the edible portion of fresh apples contains a significant amount of different classes of phenolic compounds, which can protect the human body against oxidative stress by scavenging oxygen free radicals. Free radicals play a crucial role in lipid and DNA oxidation as well as in the pathogenesis of several human diseases, such as cancer, rheumatoid arthritis and various neurodegenerative and pulmonary diseases. The strong antioxidant capacity of phenolics from apples may protect human cells against these radicals and they are therefore important tools in obtaining and preserving human health. ${ }^{2}$ Cancer cell culture studies have demonstrated that apple extracts inhibit cell proliferation in vitro, which may contribute to the association of apple intake with decreased cancer risk. Studies in vivo have shown that consumption of apples significantly lowers lipid oxidation both in humans and rats and lowers cholesterol level in humans. These effects, which may be attributed to both the phenolics and the dietary fiber found in apples, may partially explain the inverse association of apple intake and risk of cardiovascular disease. ${ }^{3}$

Fresh juices may potentially contain the same range of phenolic compounds as the apples from which

\footnotetext{
$\uparrow$ Presented at the $10^{\text {th }}$ International Symposium and Summer School on Bioanalysis within the CEEPUS Network CII-HU-001004-0910, Zagreb, Croatia, July 2010.

* Author to whom correspondence should be addressed. (E-mail: iva.juranovic-cindric@chem.pmf.hr)
} 
they are derived, although due to differences among different varieties of apples and their origin, total phenolic content of apple juice will vary considerably. Moreover, some of the phenolic compounds will be lost, and others will increase during juice production, packaging, and storage. Apple phenolics have been found to bind with cell wall material, which could lead to the decreased levels of phenolic compounds found in apple juices. ${ }^{4}$ Processing of apples has been found to affect content of bioactive substances of apple juice. Apple juice obtained from Jonagold apples by pulping and straight pressing had $10 \%$ of the antioxidant capacity of fresh apples, while juice obtained after pulp enzyming had only $3 \%$ of antioxidant capacity. ${ }^{5}$ Similarly, Guyot et al., (2003, Ref. 6) found that $42 \%$ of total phenolics were extracted in the juice, leaving over half the total phenolics in the apple pomace.

Intake of phenolics in common human diet was recently estimated as average $18-31 \mathrm{mg} /$ day in the Spanish diet, with wine and apples being the main source. Similarly, average consumption of phenolic in the Dutch diet was estimated to be $50 \mathrm{mg} /$ day. ${ }^{7}$ The reported total dietary intake of phenolics to be approximately $1 \mathrm{~g}$ /day, regardless of the methods used (HPLC or the Folin-Ciocalteu method) for the determination of the concentration. ${ }^{8}$

Thus the quantitative analysis of beneficial components, such as those responsible for the antioxidative capacity is of great interest. The Folin-Ciocalteu reagent method is used in the determination of total phenolics in fruits. ${ }^{9,10}$ The method is based on the reduction of phosphotungstic acid in alkaline solution to phosphotungstic blue. The absorbance of formed phosphotungstic blue is proportional to the number of aromatic phenolic groups and is used for their determination, expressed with gallic acid as the calibrant. ${ }^{11}$

For the measurement of the antioxidant capacity the colorimetric method the radical cation 2,2'azinobis(3-ethylbenzothiazoline-6-sulfonate) $\left(\mathrm{ABTS}^{\cdot+}\right)$ was used. ${ }^{12}$ Trolox $^{\circledR}$ equivalent antioxidant capacity (TEAC) assay is used for screening on potential antioxidant capacity. ${ }^{13-15}$ In literature phenolic compounds of apple juice are the major contributors to its TEAC antioxidant capacity. Furthermore, the phenolic content and the TEAC of fruits seem to be regulated by environmental and post-harvest factors, including fruit season, fruit maturity, light exposure, storage and processing. ${ }^{12}$

These above described methods for the quantitative analysis of phenolics as well as determination of the antioxidative capacity of food stuff are based on the extraction of the compounds under study using an organic solvent. In case of beverages (aqueous solutions) an extraction step with acetone is not possible because of the miscibility of water and acetone. Acetone might have an influence on the compounds responsible for the antioxidative capacity. Aim of the presented investigation was quantitative analysis of phenolics as well as determination of the total antioxidative capacity of apple juice. Apple juice samples were analyzed without organic solvent as well as mixed with acetone to see differences caused by the solvent. Furthermore skipping the organic solvent reduces labor time and chemicals. Both methods (Folin-Ciocalteu and ABTS assay) were performed directly with self made apple juice as well as mixtures of the same apple juices with acetone for testing the applicability of the solvent-free procedure.

\section{EXPERIMENTAL}

\section{Apparatus}

$\mathrm{UV} / \mathrm{Vis}$ spectrophotometric measurements of apple juice and mixtures of apple juices with acetone were carried out in triplicates on the Varian Cary 3 absorption spectrophotometer.

\section{Samples and Sample Preparation}

Freshly harvested apples (Malus domestica. Var. Idared) from a local orchard in Velika Gorica (N 45.7173 - E 16.0571 A $107 \mathrm{~m}$ ) were obtained in September 2009 and stored at $4{ }^{\circ} \mathrm{C}$ (refrigerator). The average sample consisted of representative amounts of five individual samples $(1 \mathrm{~kg})$ from the same orchard, in similar stage of biological development and ripeness. The quality of the raw material was relatively stable since all the experiments were completed within one month.

Six samples of whole apples (flesh + peel) were cut with a plastic knife and fresh juice was prepared in a commercial juicer (Silva homeline). The juice was divided in two fractions. One part $(5 \mathrm{~mL})$ was mixed with $10 \mathrm{~mL}$ pure acetone (mass concentration, $\gamma=1: 7 \mathrm{~g} / \mathrm{mL}$ ) for 20 minutes at room temperature using an ultrasonic bath. These clear solutions (fraction I) and the clarified apple juices (fraction II) underwent the further spectrophotometric determination. All samples were prepared in triplicate. For the blank solutions distilled water was taken instead of apple juice and treated in the same manner.

\section{Folin-Ciocalteu Method}

Total phenolic content was determined spectrophotometrically according to the Folin-Ciocalteu's method ${ }^{16}$ with slight modification. Briefly, $0.5 \mathrm{~mL}$ of the sample was pipetted into a $10 \mathrm{~mL}$ volumetric flask containing $0.5 \mathrm{~mL}$ of Folin-Ciocalteu's reagent, $5 \mathrm{~mL}$ of distilled water and $1.5 \mathrm{~mL}$ of $\mathrm{Na}_{2} \mathrm{CO}_{3}$ solution $(w=20 \%)$, and the volume was made up with distilled water. During the oxidation of phenolic compounds, phosphomolybdic 
Table 1. Total antioxidant capacity and total phenolic content of apple juices and mixture of apple juice with acetone (values given as means $\pm \mathrm{SD}$ ) and student's $t$-values of test of significance for differences of means

\begin{tabular}{ccccc}
\hline \multirow{2}{*}{ sample } & \multicolumn{2}{c}{ pure apple juice $^{\text {Total }}$} & \multicolumn{2}{c}{ juice with acetone } \\
\cline { 2 - 5 } & $\begin{array}{c}\text { Total } \\
\text { content of phenolics }^{(\mathrm{a})}\end{array}$ & $\begin{array}{c}\text { Total } \\
\text { antioxidant capacity }\end{array}$ & $\begin{array}{c}\text { (b) } \\
\text { content of phenolics }^{(\mathrm{a})}\end{array}$ & $\begin{array}{c}\text { Total } \\
\text { antioxidant capacity }^{(\mathrm{b})}\end{array}$ \\
\hline apple juice 1 & $481 \pm 3$ & $1.39 \pm 0.15$ & $394 \pm 4$ & $1.20 \pm<0.01$ \\
apple juice 2 & $546 \pm 6$ & $1.52 \pm<0.01$ & $457 \pm 6$ & $1.25 \pm 0.01$ \\
apple juice 3 & $413 \pm 10$ & $1.23 \pm 0.02$ & $458 \pm 2$ & $1.44 \pm 0.02$ \\
apple juice 4 & $537 \pm 4$ & $1.29 \pm<0.01$ & $409 \pm 5$ & $1.24 \pm 0.01$ \\
apple juice 5 & $622 \pm 4$ & $1.60 \pm<0.01$ & $563 \pm 2$ & $1.59 \pm<0.01$ \\
apple juice 6 & $644 \pm 7$ & $1.33 \pm 0.01$ & $592 \pm 6$ & $1.04 \pm 0.01$ \\
median & $542 \pm 6$ & $1.36 \pm 0.01$ & $458 \pm 4$ & $1.25 \pm 0.01$ \\
$t$-values & $0.05^{(\mathrm{c})}$ & $0.25^{(\mathrm{c})}$ & & \\
\hline
\end{tabular}

(a) Expressed as mg GAE/L.

(b) Expressed as mmol Trolox ${ }^{\circledR} / \mathrm{L}$.

(c) Comparison between pure juice and mixture with acetone.

and phosphotungstic acid, contained in the FolinCiocalteu's reagent, were reduced to blue-colored molybdenum and tungsten oxides. After two hours, the absorbance of blue coloration was measured at $\lambda=765$ $\mathrm{nm}$ against a blank sample. The measurements were compared to a standard curve of prepared gallic acid solutions $\left(50,100,150,250,500 \mathrm{mg} \mathrm{L}^{-1}\right)$ and expressed as milligrams of gallic acid equivalents per $100 \mathrm{~g} \pm \mathrm{SD}$. All measurements were performed in triplicate.

\section{ABTS Assay}

The total antioxidant capacity of the apple samples was evaluated according with the decolorization of the ABTS radical cation $\left(\mathrm{ABTS}^{\cdot+}\right.$ ) as percentage inhibition. ABTS was dissolved in water to a concentration of 7 mmol L ${ }^{-1}$. ABTS radical cation $\left(\mathrm{ABTS}^{\circ+}\right.$ ) was produced by reacting ABTS stock solution with potassium persulfate $\left(c\left(\mathrm{~K}_{2} \mathrm{~S}_{2} \mathrm{O}_{8}\right)=2.45 \mathrm{mmol} \mathrm{L} \mathrm{L}^{-1}\right)$ and allowing the mixture $(1: 1)$ to stand in the dark at room temperature for $16 \mathrm{~h}$ before use. The $\mathrm{ABTS}^{*+}$ working solution was prepared by dissolving $\mathrm{ABTS}^{\circ+}$ radicalized solution in ethanol (1:50) to an absorbance of $0.700 \pm 0.20$ at $\lambda=734 \mathrm{~nm}$. The wavelength selected for the assay was $734 \mathrm{~nm}$ corresponding to the highest extinction coeffcient $\left(\varepsilon=1.7 \times 10^{4} \mathrm{~mol}^{-1} \mathrm{~L} \mathrm{~cm}^{-1}\right.$ in ethanol). The reaction was started by adding exact volume of the sample to the cuvette containing the radical $\mathrm{ABTS}^{\circ+}\left(c \mathrm{ABTS}^{\cdot+}\right)$ $=0.9 \mathrm{mmol} \mathrm{L}^{-1}$ ). The discoloration following the sample addition indicates that ABTS radical cations were quenched or reduced by the antioxidants in the sample was determined by measuring the decrease of absorbance at $734 \mathrm{~nm}$ for $60 \mathrm{~min}$ at $25{ }^{\circ} \mathrm{C}$. The percentage inhibition of absorbance at $734 \mathrm{~nm}$ is calculated and plotted as a function of concentration of antioxidants and of Trolox ${ }^{\circledR}$ for the standard reference data. Working solution of Trolox ${ }^{\circledR}(c$ (Trolox $\left.)=2.5 \mathrm{mmol} \mathrm{L}^{-1}\right)$ was prepared in ethanol. A linear relationship was observed for absorbance decrease versus Trolox ${ }^{\circledR}$ concentration $\left(r^{2}=\right.$ 0.999). The percentage inhibition of decolorization values (TEAC) were calculated as:

$$
\mathrm{TEAC}=\left(1-\frac{\text { Absorbance }_{7 \text { min after reaction }}}{\text { Absorbance }_{\text {initial }}}\right) \times 100
$$

and expressed using Trolox ${ }^{\circledR}$ equivalents per liter following the nomenclature of Rice-Evans et al. (1994). ${ }^{17}$ The TEAC value for Trolox ${ }^{\circledR}$ is 1 . All samples were made in triplicate. The coefficient of variation was always less than $5 \%$.

\section{Statistics}

All standard deviations are based on measurements in triplicate. The results obtained for both methods with and without acetone were compared using a paired $t$-test in order to see statistically significant differences in the results at the level of significance of 0.05 .

\section{RESULTS}

The antioxidant capacity of samples are expressed using mmol of Trolox ${ }^{\circledR}$ equivalents per liter of fresh juice (Table 1). All data were reported as mean $\pm \mathrm{SD}$ of three replicates. The medians of the total antioxidant capacity determined by ABTS radical cation in apple juice and in acetonic mixtures were $(1.36 \pm 0.01) \mathrm{mmol}^{\text {Trolox }}{ }^{\circledR} / \mathrm{L}$ and $(1.25 \pm 0.01)$ mmol Trolox $^{\circledR} / \mathrm{L}$, respectively. Similar 
results $(1.10-1.95)$ mmol $\operatorname{Trolox}^{\circledR} / \mathrm{L}$ were reported by Gliszczynska-Swiglo et al., (2003), ${ }^{12}$ lower concentration $\left(0.840 \mathrm{mmol}^{\text {Trolox }}{ }^{\circledR} / \mathrm{L}\right)$ by Miller et. al., (1997, Ref. 11) and higher (3.06-5.32 mmol Trolox ${ }^{\mathbb{B} /}$ L) by S. Karaman et al., (2010). ${ }^{18}$

The median content of phenolics in the samples are expressed as $\mathrm{mg}$ of gallic acid equivalents (GAE) per liter of fresh apple juice (Table 1). The total content of phenolics determined by Folin-Ciocalteu method in apple juice and in acetonic mixtures of apple juice were (542 \pm 5$) \mathrm{mg} \mathrm{GAE} / \mathrm{L}$ and $(458 \pm 4) \mathrm{mg} \mathrm{GAE} / \mathrm{L}$, respectively. Assuming an average polyphenol intake of $1 \mathrm{~g}$ per day, or about $420 \mathrm{~mL}$ of apple juice would need to be consumed.

The results obtained for both methods with and without acetone were compared using a paired $t$-test in order to see statistically significant differences in the results. The medians for total phenolic content and antioxidative capacity were lower in case of acetonic mixtures, but at the chosen level of significance of 0.05 these differences between pure apple juices and their mixtures with acetone were found not to be statistically significant.

\section{CONCLUSION}

Thus the time of analysis, the amount of solvents needed, and the required labor force can be reduced without loosing analytical quality. No differences were found in the content of phenolics as well as in their antioxidant capacity between the apple juice and its acetonic mixtures.

\section{REFERENCES}

1. Zentrale Markt- und Preisberichtstelle für Erzeugnisse der Land-, Forst- und Ernährungswirtschaft GmbH (ZMP) (2002) Entwicklung des Fruchtsaftverbrauches. Bonn.

2. M. J. T. J. Arts, G. R. M. M. Haenen, H.-P. Voss, and A. Bast, Food Chem. Toxicol. 42 (2004) 45-49.

3. J. Boyer and R. H. Liu, Nutr. J. 3 (2004) 1-15.

4. R. C. Baron and G. S. Drilleau, Int. J. Biol. Macromol. 29 (2001) 115-125.

5. A. Sluis, M. Dekker, G. Skrede, and W. Jongen, J. Agric. Food Chem. 50 (2002) 7211-7219.

6. S. Guyot, N. Marnet, P. Sanoner, and J. Drilleau, J. Agric. Food Chem. 51 (2003) 6240-6247.

7. T. Shoji, Y. Akazome, T. Kanda, and M. Ikeda, Food Chem. Toxicol. 42 (2004) 959-967.

8. A. Scalbert and G. Williamson, J. Nutr. 130 (2000) S-2085S.

9. D. Marinova, F. Ribarova, and M. Atanassova, J. Univ. Chem. Technol. Metall. 40 (2005) 255-260.

10. G. Rusak, D. Komes, S. Likić, D. Horžić, and M. Kovač, Food Chem. 110 (2008) 852-858.

11. V. L. Singleton, R. Orthofer, and R. M. Lamuela-Raventos, Methods in Enzymology, Oxidants and Antioxidants, San Diego: Academic Press. 299 (1999) 152-178.

12. R. Re, N. Pellegrini, A. Proteggente, A. Pannala, M. Yang, and C. Rice- Evans, Free Radical Biol. Med. 26 (1999) 1231-1237.

13. M. J. T. J. Arts, J. S. Dallinga, H.-P. Voss, G. R. M. M. Haenen, and A. Bast, Food Chem. 88 (2004) 567-570.

14. N. J. Miller and C. A. Rice-Evans, Food Chem. 60 (1997) 331-337.

15. A. Gliszczynska-Swiglo and B. Tyrakowska, J. Food Sci. 68 (2003) 1844-1849.

16. J. Lachman, V. Hosnedl, V. Pivec, and M. Orsak, Proceedings of the Conference Cereals for Human Health and Preventive Nutrition (1998) 118-125.

17. C. A. Rice-Evans and N. J. Miller, Methods Enzymol. 234 (1994) 279-293.

18. S. Karaman, E. Tuetem, K. S. Baskan, and R. Apak, Food Chem. 120 (2010) 1201-1209. 